\title{
The Mechanism of Denervation Natriuresis *
}

\author{
Donald E. Kamm $\dagger$ and Norman G. Levinsky $\ddagger$ \\ (From the Fifth and Sixth [Boston University] Medical Services, Boston City Hospital, and \\ the Department of Medicine, Boston University Medical Center, Boston, Mass.)
}

Acute or chronic denervation of the kidney results in a moderate increase in electrolyte and water excretion, often described as a "denervation diuresis" (1-12). The mechanism of the natriuresis that is a feature of this phenomenon remains controversial. A number of investigators (1-5) have suggested that nerves alter sodium excretion indirectly by controlling renal hemodynamics, because in their studies there was a rise in filtered sodium large enough to explain the sodium diuresis. Other workers $(6-12)$ have concluded that denervation depresses tubular transport of sodium. At least two factors probably account for the conflicting conclusions. First, there is the technical problem of accurately measuring the small changes in filtered sodium that occur after section of renal nerves. Second, there are no independent data from which one can determine the effect of an increase in filtered sodium uncomplicated by a change in tubular reabsorptive capacity. Therefore, even if a small increase in filtered sodium after nerve section is reliably demonstrated, it is uncertain how large an increase in sodium excretion can be ascribed solely to this change. Results that demonstrate a simultaneous rise in sodium excretion and filtered sodium after denervation, although suggestive, do not conclusively separate a cause and effect relation from simple association.

* Submitted for publication July 29, 1964 ; accepted September 22, 1964.

Supported in part by U. S. Public Health Service research grants HE-06795 from the National Heart Institute and AM 05589-03 from the National Institute of Arthritis and Metabolic Diseases.

Presented in part at the Annual Meeting of the Federation of American Societies for Experimental Biology, Chicago, April 1964, and abstracted in Fed. Proc. 1964, 23, 306.

$\dagger$ Postdoctoral fellow (5- $\left.\mathrm{F}_{2}-\mathrm{HE} 16050-02\right)$ of the National Heart Institute.

¥ Address all correspondence to Dr. Norman G. Levinsky, Boston University Medical Research Building, 15 Stoughton Street, Boston, Mass. 02118.
To circumvent some of these difficulties, we have used an arterial clamp to decrease postdenervation sodium excretion to predenervation values. This technic permits direct measurement of tubular reabsorption at equal rates of sodium excretion before and after denervation. The approach is based on the assumption that if tubular reabsorption is not altered by denervation, filtered sodium will be found at predenervation levels when sodium excretion is returned to the predenervation rate. If, on the contrary, a decrease in tubular capacity occurs, filtered sodium should be below predenervation levels when the denervation diuresis has been eliminated. The technical problems of accurately measuring the small changes in filtered sodium that occurred in the present studies preclude definitive analysis of individual experiments. Statistical analysis of all experiments, however, demonstrates that the increase in filtered sodium after denervation was approximately three times as great as the increase in sodium excretion. When sodium excretion was returned to predenervation levels by clamping, filtered sodium was found to be at, rather than below, predenervation values. These results show that there is no change in tubular function following denervation and indicate that denervation natriuresis can be completely explained by an associated rise in glomerular filtration rate (GFR).

\section{Methods}

Since it is difficult to evaluate the significance of absolute changes in excretion during the course of prolonged experiments, the effects of denervation were studied in each dog by comparing the two kidneys, one acutely denervated and one innervated. The ratios of sodium excretion and GFR, experimental over control kidney ( $\mathrm{U}_{\mathrm{Na}} \mathrm{V}$ E/C, GFR E/C), were used to evaluate the effects of denervation and clamping. With one exception, 1 experiments were discarded if the difference in

1 In experiment 1 (Table I), although the difference in excretion between the two kidneys did not increase $50 \mu \mathrm{Eq}$ per minute after denervation, $\mathrm{U}_{\mathrm{Na}} \mathrm{V} \mathrm{E} / \mathrm{C}$ increased from 1.51 to 2.27 . 
TABLE I

Summary of all experiments

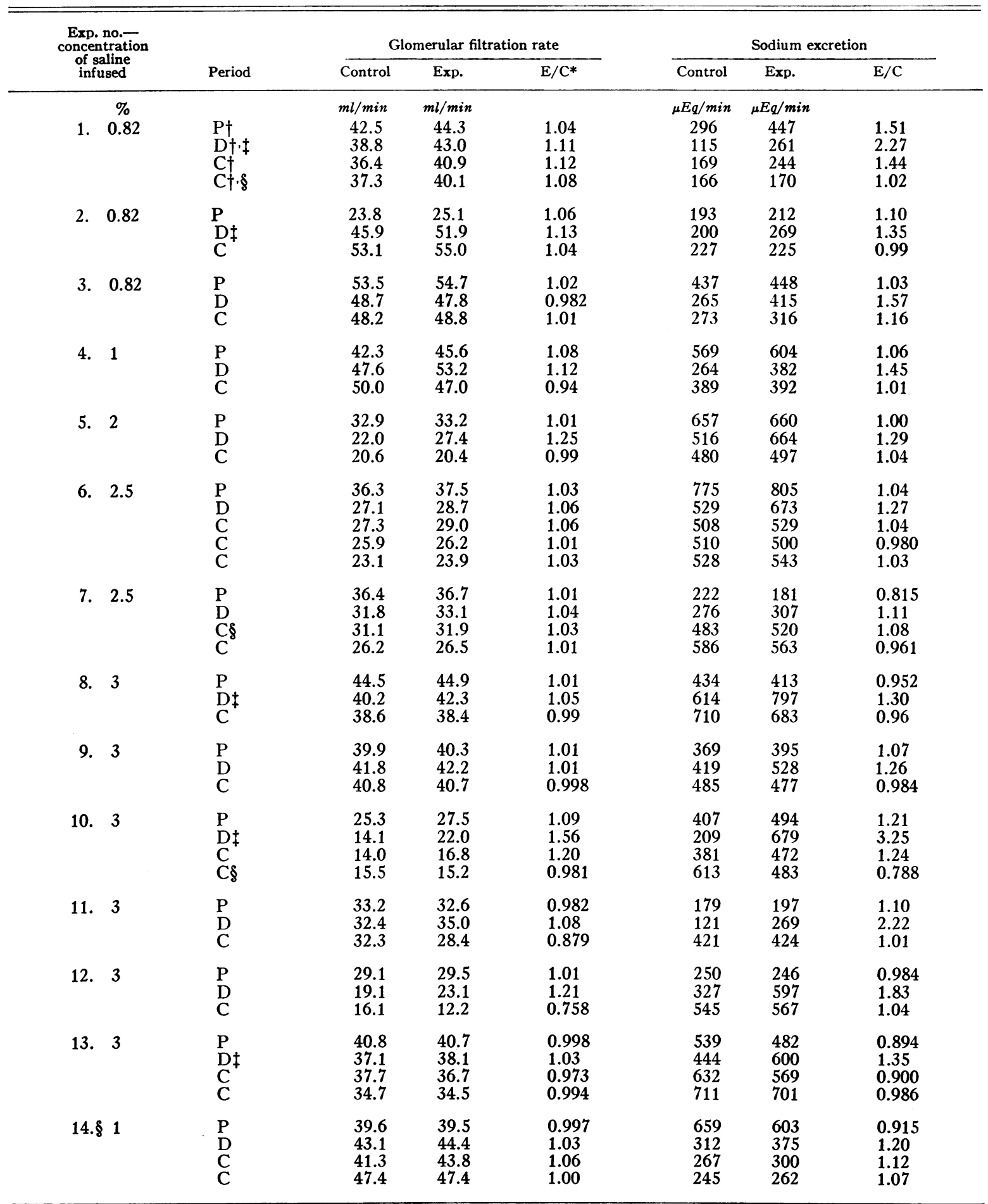

* Experimental/control.

$\dagger \mathrm{P}=$ predenervation; $\mathrm{D}=$ denervation; $\mathrm{C}=$ clamp collections. Each value is the mean of three or more periods. $\ddagger$ Denervation procedure included stripping renal pedicle.

$\$$ Group of periods or experiment not included in statistical treatment (see Methods). 
TABLE I-(Continued)

\begin{tabular}{|c|c|c|c|c|c|c|c|}
\hline \multirow{2}{*}{$\begin{array}{l}\text { Exp. no.-- } \\
\text { concentration } \\
\text { of saline } \\
\text { infused }\end{array}$} & \multirow[b]{2}{*}{ Period } & \multicolumn{3}{|c|}{ Glomerular filtration rate } & \multicolumn{3}{|c|}{ Sodium excretion } \\
\hline & & Control & Exp. & $\mathrm{E} / \mathrm{C}^{*}$ & Control & Exp. & $\mathrm{E} / \mathrm{C}$ \\
\hline$\%$ & & $m l / m i n$ & $\operatorname{ml} / \min$ & & $\mu E q / \min$ & $\mu E q / \min$ & \\
\hline $15 . \S 3$ & $\begin{array}{l}\mathrm{P} \\
\mathrm{D} \\
\mathrm{C} \\
\mathrm{C}\end{array}$ & $\begin{array}{l}33.2 \\
34.0 \\
35.5 \\
41.4\end{array}$ & $\begin{array}{l}33.5 \\
36.5 \\
37.5 \\
41.5\end{array}$ & $\begin{array}{l}1.01 \\
1.07 \\
1.06 \\
1.00\end{array}$ & $\begin{array}{l}350 \\
425 \\
684 \\
917\end{array}$ & $\begin{array}{l}401 \\
696 \\
650 \\
902\end{array}$ & $\begin{array}{l}1.15 \\
1.64 \\
0.950 \\
0.984\end{array}$ \\
\hline $16 . \S 3.6$ & $\begin{array}{l}\mathrm{P} \\
\mathrm{D} \\
\mathrm{C}\end{array}$ & $\begin{array}{l}32.7 \\
21.8 \\
21.7\end{array}$ & $\begin{array}{l}35.8 \\
28.3 \\
21.1\end{array}$ & $\begin{array}{l}1.09 \\
1.30 \\
0.97\end{array}$ & $\begin{array}{l}715 \\
319 \\
563\end{array}$ & $\begin{array}{l}954 \\
945 \\
513\end{array}$ & $\begin{array}{l}1.33 \\
2.96 \\
0.911\end{array}$ \\
\hline$\underset{1-13}{M}$ & $\begin{array}{l}\mathrm{P} \\
\mathrm{D} \\
\mathrm{C}\end{array}$ & & & $\begin{array}{l}1.03 \pm 0.03 \\
1.13 \pm 0.15 \\
1.00 \pm 0.09\end{array}$ & & & $\begin{array}{l}1.06 \pm 0.17 \\
1.66 \pm 0.60 \\
1.05 \pm 0.13\end{array}$ \\
\hline$p$ values & $\begin{array}{l}P \text { vs. } D \\
D \text { vs. } C \\
C \text { vs. } P\end{array}$ & & & $\begin{array}{l}<.05 \\
<.02 \\
>.05\end{array}$ & & & $\begin{array}{l}<.01 \\
<.01 \\
>.05\end{array}$ \\
\hline
\end{tabular}

sodium excretion between the two kidneys did not increase by $50 \mu \mathrm{Eq}$ per minute or more after denervation. Sixteen of 24 experiments met this criterion for a significant denervation natriuresis and are included in this paper.

Food and water were withdrawn from female mongrel dogs about 16 hours before experiments. The dogs were anesthetized with pentobarbital, $30 \mathrm{mg}$ per $\mathrm{kg}$ intravenously; small supplementary doses were given as necessary to maintain light anesthesia. After appropriate priming doses of inulin', a sustaining infusion of inulin in $3 \%$ dextrose in water was given at approximately $0.5 \mathrm{ml}$ per minute. Urine was collected separately from each kidney through polyethylene tubing that had been inserted into the ureters through a midline lower abdominal incision. The left greater splanchnic nerve was isolated and surrounded with a loose tie through a left subcostal incision. This was done before predenervation collections in 12 and after predenervation collections in four experiments. A saline infusion, varying from 0.8 to $3.6 \%$ in different experiments, was given at 7 to $20 \mathrm{ml}$ per minute for 15 to 45 minutes and then at 3 to $6 \mathrm{ml}$ per minute during the remainder of the experiment.

When sodium excretion from each kidney was at least $150 \mu \mathrm{Eq}$ per minute and relatively stable, three to five "predenervation" clearance collections were made. The splanchnic nerve was then transected; in five experiments, the renal pedicle was also stripped of nervous tissue. When it became apparent that denervation had resulted in a significant increase in sodium excretion (10 minutes to 2.5 hours after denervation), the "denervation" collections were made. A modified Blalock clamp that had been placed around the artery to the denervated kidney ${ }^{2}$ was then tightened until $\mathrm{U}_{\mathrm{Na}} \mathrm{V} \mathrm{E} / \mathrm{C}$ was ap-

2 The clamp was positioned before predenervation collections in two experiments, at the time of denervation in proximately equal to the ratio present before denervation. It was usually necessary to reset the clamp several times before the desired sodium excretion ratio was obtained. When measurements of urinary sodium made during the experiment indicated that the appropriate setting had been achieved, a group of consecutive "clamp" collections were made. Occasionally, clearance collections were also made at other clamp settings. All clearance collections from all 16 experiments in which a denervation natriuresis developed are included in Table I. Since the purpose of these experiments was to measure GFR E/C before and after denervation at the same $\mathrm{U}_{\mathrm{Na}} \mathrm{V} \mathrm{E} / \mathrm{C}$, experiments or clamp settings in which $\mathrm{U}_{\mathrm{Na}} \mathrm{V} \mathrm{E} / \mathrm{C}$ after denervation was not returned to within $\pm 15 \%$ of predenervation values are not included in the main presentation of the results. Such data are marked by the symbol $\S$ in Table I.

Inulin clearance $\left(C_{I n}\right)$ was used as a measure of GFR, and filtered sodium $\left(F_{\mathrm{Na}_{\mathrm{a}}}\right)$ was calculated as equal to plasma sodium concentration $\left(\mathrm{P}_{\mathrm{N}_{2}}\right) \times \mathrm{C}_{\mathrm{In}}$. Since two kidneys in the same dog were being compared, no correction for the Donnan factor was made in calculating filtered sodium. The analytical methods used in these studies have been listed elsewhere (13). Statistical significance was evaluated by the Fisher $t$ test. In the case of two comparisons, GFR E/C and $U_{\mathrm{Na}_{2}} \mathrm{E} / \mathrm{C}$ clamp versus predenervation periods, the value of $p$ was calculated both from group means and from paired analysis of individual experiments. There was no difference in the values of $\mathrm{p}$ obtained by these two methods.

\section{Results}

The effect of denervation on filtered sodium and sodium excretion. The data from all 16 experiments in which a significant denervation natriure-

three experiments, and after the "denervation" collections in the remaining experiments. 


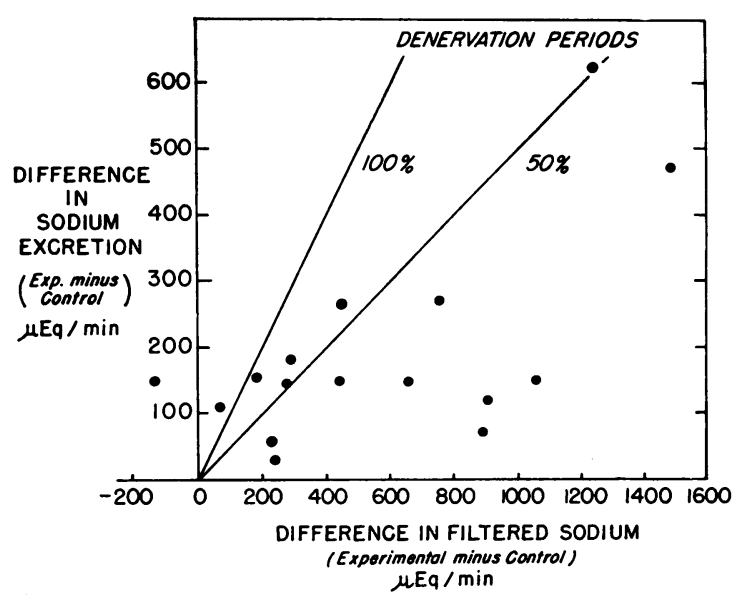

Fig. 1. Relation of The Difference in SOdium EXCRETION BETWEEN DENERVATED AND CONTROL KIDNEYS TO THE DIFFERENCE IN FILTERED SODIUM IN 16 EXPERIMENTS. The $100 \%$ line indicates equal differences in excreted and filtered sodium. The $50 \%$ line indicates a difference in excretion equal to one-half of the difference in filtered sodium.

sis developed are summarized in Table I. Each value in this Table is the mean of three or more periods. The differences in filtered and excreted sodium between the two kidneys after denervation are illustrated in Figure 1. The difference in sodium excretion, plotted on the ordinate, is compared with the difference in filtered sodium, plotted on the abscissa. Each point represents the mean of three or more collection periods from a single experiment. As can be seen, the absolute magnitude of the difference in sodium excretion due to denervation is small, varying from 30 to $625 \mu \mathrm{Eq}$ per minute in the 16 experiments. In 15 of 16 experiments, filtered sodium was higher on the experimental than on the control side. Fourteen of the 16 points fall to the right of the $100 \%$ line, which represents equal changes in filtered and excreted sodium. This indicates that in these 14 experiments the increase in sodium excretion could be explained by an associated increase in filtered sodium if all or part of this increase were excreted. Eleven of the experiments are on or to the right of the $50 \%$ line, indicating that excretion of half or less of the increase in filtered sodium would account for the denervation natriuresis. The mean increase in sodium excretion in all 16 experiments was equal to about one-third of the corresponding increase in filtered sodium.

The effect of renal artery clamping. The data from a single complete experiment are illustrated in Figure 2. During the predenervation collections sodium excretion was about $20 \mu \mathrm{Eq}$ per minute lower on the experimental side, giving an excretion ratio, $\mathrm{E} / \mathrm{C}$, of about 0.95 . Since the

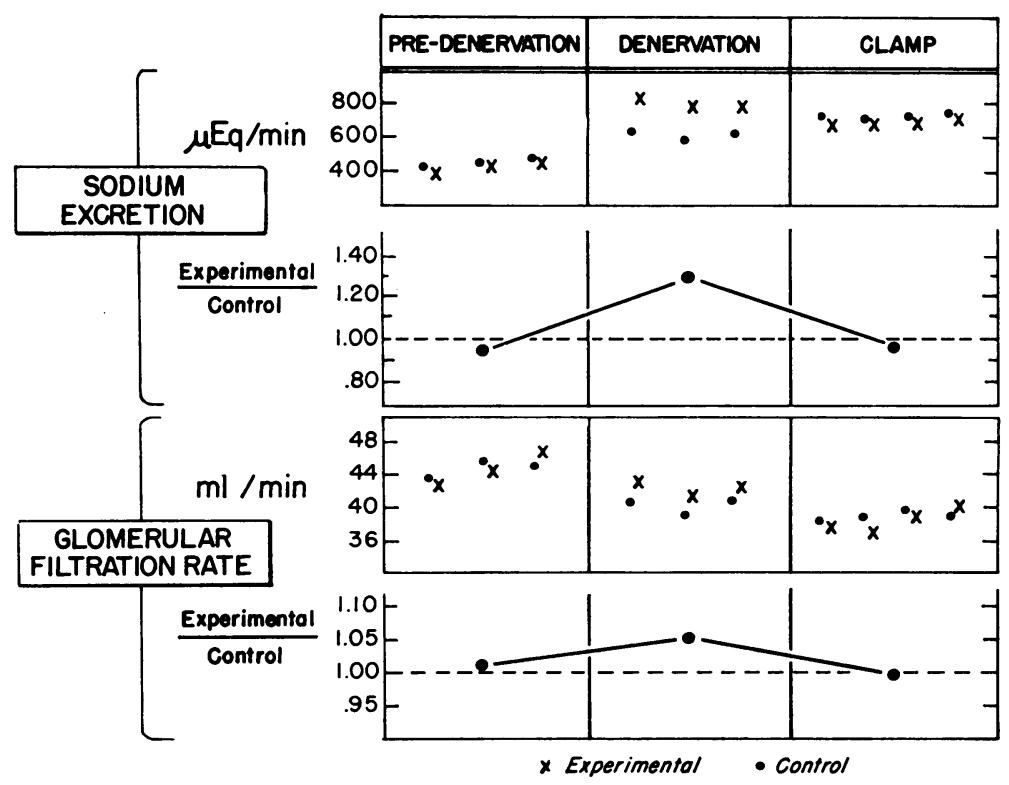

Fig. 2. Detailed plot of the absolute values and mean ratios of soDIUM EXCRETION AND GLOMERULAR FILTRATION RATE IN A REPRESENTATIVE EXPERIMENT. 


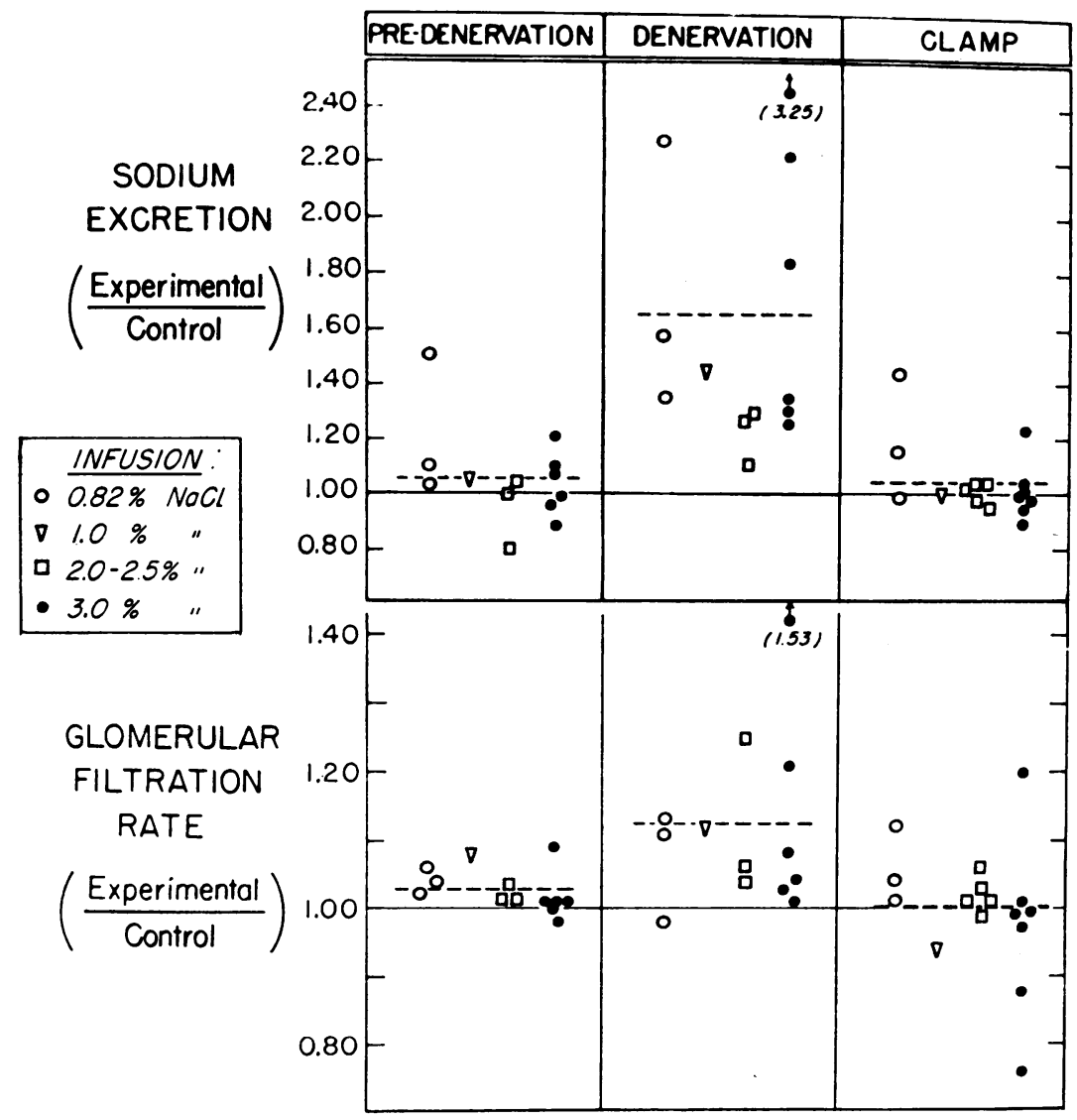

Fig. 3. MASS PLOT OF THE MEAN RATIOS OF SODIUM EXCRETION AND GLOMERULAR FILTRATION RATE IN ALL 13 EXPERIMENTS.

predenervation filtration rates were about equal, the GFR ratio was close to one. After unilateral denervation sodium excretion rose to about 800 $\mu \mathrm{Eq}$ per minute on the experimental side; excretion from the control kidney spontaneously rose to $600 \mu \mathrm{Eq}$ per minute, presumably due to continued loading with hypertonic saline. Thus, the sodium excretion ratio increased from the predenervation value of 0.95 to 1.30 . At the same time, although the total GFR fell somewhat, the filtration rate of the denervated kidney was slightly greater than that of the control. The difference in excretion of about $200 \mu \mathrm{Eq}$ per minute between the kidneys was equal to about one-half of the difference in filtered sodium. Sodium excretion from the experimental kidney was then reduced with the renal artery clamp until it was slightly less than that from the control kidney, approximating the predenervation ratio of 0.95 . The filtration rates of the two kidneys were now found to be equal, and the GFR ratio closely approximated its predenervation value.

The data from all 13 experiments in which the sodium excretion ratio during the clamp periods was brought to within $15 \%$ of its predenervation value are summarized in Table $I$ and Figure 3. During all but two of the clamp periods the sodium excretion ratio was within $10 \%$ of the predenervation value. Each point in Figure 3 represents the mean of three to six collection periods in one experiment; broken lines represent over-all means for all 13 experiments. During the predenervation periods mean sodium excretion and mean GFR were both slightly higher on the experimental side. After denervation, $\mathrm{U}_{\mathrm{Na}} \mathrm{V}$ E/C increased from 19 to $204 \%$ above previous values; the mean ratio rose to 1.66 , a value significantly different from the predenervation mean of 1.06 $(\mathrm{p}=<0.01)$. At the same time, GFR E/C increased 3 to $49 \%$ in 11 experiments, was un- 
changed in one, and fell $4 \%$ in another. The mean denervation GFR E/C of 1.13 was significantly different from the predenervation ratio of $1.03(\mathrm{p}=<0.05)$.

Sodium excretion from the denervated kidney was appropriately reduced, and $\mathrm{U}_{\mathrm{Na}} \mathrm{V}$ E/C returned to within $\pm 15 \%$ of the predenervation ratio during 16 clamp clearances. Two clamp settings within these limits were obtained in one and three in another of the 13 experiments. The mean clamp $\mathrm{U}_{\mathrm{Na}} \mathrm{V} \mathrm{E} / \mathrm{C}$ ratio was 1.05 , a value not significantly different from the mean predenervation ratio of 1.06 . It was, however, significantly different from the mean denervation $\mathrm{U}_{\mathrm{Na}} \mathrm{V}$ E/C of $1.66(p<0.01)$. The GFR changes associated with the return of sodium excretion to control values are shown in the lower half of Figure 3. With respect to its predenervation value, clamp GFR E/C was elevated during three, reduced during four, and the same $( \pm 2 \%)$ during nine clamp settings. The mean clamp GFR E/C of 1.00 was not significantly different from the mean predenervation value of 1.03 , but was significantly different from the denervation GFR ratio of 1.13 ( $p<0.02$ ). Thus, reduction of $\mathrm{U}_{\mathrm{Na}} \mathrm{V}$ $\mathrm{E} / \mathrm{C}$ to predenervation values by clamping was associated with a fall in GFR E/C to the predenervation level.

Three experiments are illustrated in Figure 4. Sodium excretion ratios are shown in the upper half and GFR ratios in the lower half of the figure. Each point represents the mean of three or more predenervation, denervation, or clamp periods in one experiment. Although these experiments differ from each other in several respects,

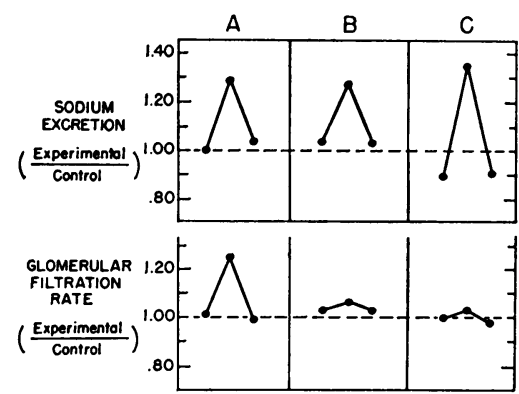

Fig. 4. Three tyPes of experiments. Experiment A shows a large change; experiments $B$ and $C$, little or no change in GFR E/C after denervation. In experiment $C$ there was a $>10 \%$ difference in sodium excretion between the two kidneys during the predenervation periods. in each the GFR ratio returned to its predenervation value when the sodium excretion ratio was brought to control levels by clamping. The first experiment is representative of the six studies (no. $1,2,5,10-12$ in Table I) in which relatively large increases in the GFR ratio were noted after denervation. In absolute terms these increases, which ranged from 7 to $47 \%$, were more than enough to acount for the rise in sodium excretion. The second and third experiments illustrate the opposite finding of a large increase in sodium excretion but relatively little change in the GFR ratio after denervation. In the seven experiments of this type (no. 3, 4, 6-9, 13 in Table I), GFR $\mathrm{E} / \mathrm{C}$ changes ranged from -4 to $4 \%$. Statistical analysis demonstrated that there was no significant difference between the mean predenervation and clamp GFR E/C when the data from the experiments grouped as above were treated separately. Thus, the magnitude of the change in GFR after denervation did not seem to condition the results of clamping.

The third experiment in Figure 4 is one of four studies in which the difference in sodium excretion between the two kidneys during predenervation collections was more than $10 \%$. Separate analysis of these four and the remaining nine studied yielded similar results. In both groups GFR E/C was not significantly different from the predenervation value, when $U_{\mathrm{Na}} \mathrm{V} E / \mathrm{C}$ was reduced to the predenervation level by clamping.

\section{Discussion}

When acute "denervation natriuresis" was eliminated by arterial clamping, GFR E/C was found to be at predenervation levels. In nine of 16 clearance collections, the GFR ratio was within $\pm 2 \%$ of the predenervation levels. The over-all mean GFR ratio after clamping was statistically indistinguishable from the predenervation value. In other words, at equal rates of sodium excretion, filtered sodium was equal before and after denervation. These data demonstrate that relative to the control kidney, tubular reabsorption of sodium is not affected by acute denervation. Denervation natriuresis, therefore, is due to an increase in GFR and, consequently, in filtered sodium. The results do not eliminate the possibility that the critical feature of the alteration in renal hemodynamics 
is a redistribution of blood flow and GFR to nephrons with relatively poor reabsorptive capacity, rather than the increase in total GFR. Since an over-all increase in GFR was demonstrated, however, and since the rise in filtered sodium was three times as great as the increase in excretion, it is unnecesary to postulate any such mechanism.

The experimental approach in these studies is open to the objection that the use of the clamping procedure to reduce GFR after denervation may introduce a possible direct effect of decreased renal arterial perfusion pressure on sodium excretion. The experiments of Tobian, Coffee, Ferreira, and Meuli (14) suggest that decreased perfusion pressure can enhance tubular reabsorption of sodium in the rat under stop-flow conditions. A similar inference has been drawn from clearance studies in the $\operatorname{dog}(15,16)$, although the decreases in sodium excretion in these studies can be explained adequately by decreases in GFR (17). If decreased renal arterial pressure enhances sodium reabsorption, one can argue that in the present experiments a decrease in tubular reabsorption due to denervation was exactly balanced by an increase in reabsorption due to reduced perfusion pressure. Such a fortuitous balance of unrelated phenomena seems unlikely, especially since the magnitude of the denervation natriuresis varied greatly (30 to $625 \mu \mathrm{Eq}$ per minute) in these experiments. Furthermore, if the changes in excretion during denervation and clamping are due to altered tubular reabsorption, it must be assumed that the observed increase in GFR after denervation and decrease during clamping had no effect on excretion. This assumption that changes in GFR do not affect excretion of sodium is at variance with many other data (17).

Several studies $(18-20)$ have demonstrated that reduction of GFR up to $40 \%$ by clamping or other technics is due to decrease in GFR per nephron unit rather than to dropping out of whole units. Since the reductions in GFR by clamping in the present experiments were always much less than this, the results presumably are not explained by dropping out of hypothetical nephron units with special reabsorptive capacities.

To determine whether any of several factors might affect the results of the present experiments, they were grouped according to 1 ) the magnitude of the increase in GFR $\mathrm{E} / \mathrm{C}$ after denervation $(>$ or $<7 \%)$; 2) the type of denervation (splanchnicectomy alone or with renal artery stripping) ; 3 ) the duration of the latent period between denervation and the appearance of a significant denervation natriuresis $(<30,30$ to 60 , $>60$ minutes) ; 4) disparity of $\mathrm{U}_{\mathrm{Na}} \mathrm{V}$ between the kidneys in the predenervation periods ( $>$ or $<$ $10 \%)$; and 5) concentration of saline infused. The conclusions drawn from the analysis of each of these groups were the same as those derived from the analysis of all 13 experiments. Obviously, whether the conclusions also apply to unanesthetized dogs or to chronic denervation cannot be determined from the present data.

A number of previous investigators (1-5) have also concluded that denervation natriuresis is due to increased GFR. Although a similar number of workers postulate a direct tubular effect of renal nerves (6-12), the data available for analysis do not support their conclusion in most cases. In three of the four experiments of Kriss, Futcher, and Goldman (6) in which filtered chloride can be calculated, it increased more than excreted chloride. The mean increase in excretion in all four experiments was about two-thirds of the increase in filtered chloride. In three papers by Kaplan and co-workers (7-9), studies were made after both acute and chronic denervation of one kidney. In all but three experiments (reference 9, Table IB, experiments $9,11,12$ ), the increase in filtered sodium was greater than the natriuresis. In most studies, the absolute increase in filtered sodium of the denervated kidney, assuming a reasonable value for plasma sodium, would be several times as great as the increase in sodium excretion. Sartorius and Burlington (10) studied acute denervation in intact dogs and in isolated kidneys perfused at various pressures. In the data from an intact dog in their Figure 1, the absolute increase in GFR of about $2 \mathrm{ml}$ per minute in the denervated kidney (presumably an increase of about $300 \mu \mathrm{Eq}$ per minute in filtered sodium) is sufficient to explain the 40 or $50 \mu \mathrm{Eq}$ per minute increase in $U_{\mathrm{Na}} \mathrm{V}$. In six studies in which kidneys were perfused at $105 \mathrm{~mm} \mathrm{Hg}$, filtered sodium was increased about $800 \mu \mathrm{Eq}$ per minute after denervation, whereas excretion increased only $10 \mu \mathrm{Eq}$ per minute. At higher pressures, sodium excretion increased only 20 to $30 \mu \mathrm{Eq}$ per minute, which 


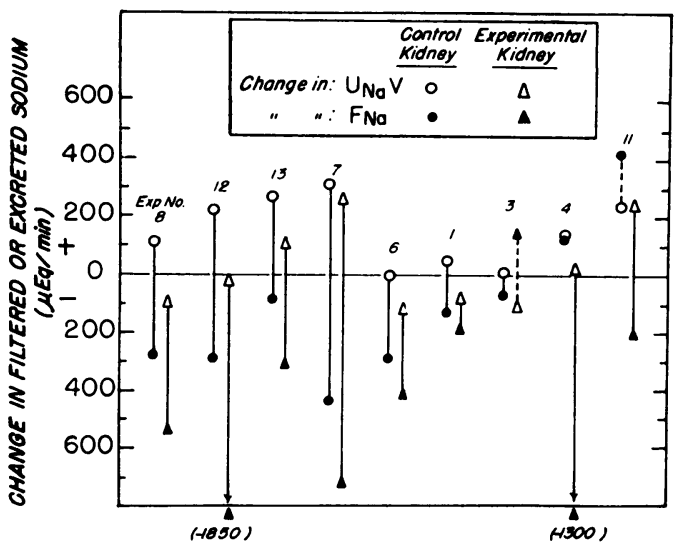

Fig. 5. COMPARISON OF THE RESPONSE TO SALINE LOADING IN DENERVATED AND INTACT KIDNEYS. The changes in sodium excretion $\left(\mathrm{U}_{\mathrm{Na}} \mathrm{V}\right)$ and filtered sodium $\left(F_{\mathrm{Na}}\right)$ between the "denervation" periods and the last "clamp" periods are plotted for nine experiments in which either kidney demonstrated an increase in sodium excretion associated with a decrease in filtered sodium. The experiments are numbered as in Table I. See text for details.

may be explained by the small increase in filtered sodium that occurred. Most of the data presented by Blake (12) supporting a tubular effect of denervation cannot be analyzed in terms of absolute changes in excreted and filtered sodium. $\mathrm{He}$ states, however, that in one-third of his experiments, excretion increased in spite of a fall in filtered sodium. The absolute increase in excretion was apparently small in these experiments (bottom of his Table I). Thus, in most papers concluding that a change in tubular reabsorption follows denervation, the absolute increase in sodium excretion is a fraction of the concurrent absolute increase in filtered sodium. The conclusion that denervation decreases tubular reabsorption is generally based on the observation that the percentage of filtered sodium excreted increased after denervation. However, such increases in fractional excretion can readily be explained by an increase in filtered load alone, as has been discussed by Berliner (21) and Wesson (17).

Two conclusions derived from the present experiments but not directly germane to the specific purpose of this study merit brief discussion. Recently it has been demonstrated in several laboratories $(13,22,23)$ that part of the increase in sodium excretion after saline infusion in the $\mathrm{dog}$ is due to some factor other than increased filtered sodium and decreased aldosterone. This "third factor" is not dilution of plasma proteins, an adrenal salt-losing hormone, or angiotensin (13). To investigate the possibility that renal nerves play a role, we have compared the two kidneys in the present experiments for evidence of third factor activity. In previous work in our laboratory, this factor has been demonstrated by an increase in sodium excretion after saline loading in spite of a decrease in filtered sodium. This combination of findings occurred in either kidney in the clamp period as compared to the denervation period in nine of 13 experiments. During the interval between these two collection periods, approximately 350 to $900 \mathrm{ml}$ of saline had been infused. The changes in excreted and filtered sodium in these nine experiments are illustrated in Figure 5. In the first six experiments, the changes in excreted sodium relative to changes in filtered sodium were similar on the denervated and control sides, with no tendency for quantitatively greater third factor effect on either side. In the seventh experiment, only the control kidney demonstrated an effect, whereas in the last two experiments, only the experimental kidney showed the third factor effect. Since the third factor response to saline loading was equal in frequency and approxinate magnitude in partially denervated and control kidneys, the response is probably not mediated by renal nerves.

Finally, it is worth noting that previous conclusions as to the change in sodium excretion to be expected from a change in $\operatorname{GFR}(17,24,25)$ are based largely on data derived from experiments in which GFR was raised by saline infusions. As discussed above, it has recently been demonstrated that a significant part of the increase in sodium excretion after saline loading is due to decreased tubular reabsorption $(13,22$, 23). Hence the effect of increased filtered load on sodium excretion cannot be calculated accurately from such data. The increase in sodium excretion after denervation was equivalent to about one-third of the increase in filtered sodium (Figure 1). If, as proposed in this paper, tubular reabsorption does not change after denervation, this fraction represents a reasonable estimate of the effect of an increase in filtered sodium uncomplicated by changes in tubular reabsorptive ca- 
pacity, at least under the particular conditions employed.

\section{Summary}

1. The mechanism by which acute denervation of the kidney increases sodium excretion has been studied by comparing denervated and intact kidneys in each of 13 saline-loaded dogs. After the collection of predenervation periods, the left greater splanchnic nerve was sectioned, and a set of "denervation" periods was obtained. A clamp around the left renal artery was then tightened until the sodium excretion ratio, experimental over control kidney, had been returned to its predenervation value.

2. After denervation the mean sodium excretion ratio rose to 1.66 , a value significantly different from the mean predenervation value of 1.06 . The mean glomerular filtration rate (GFR) ratio also increased significantly from 1.03 to 1.13 .

3. During the "clamp" periods the mean sodium excretion ratio was returned to 1.05 , a value not significantly different from the mean predenervation ratio of 1.06 . With the sodium excretion. thus returned to predenervation values, the mean clamp GFR ratio was found to be 1.00 , a value not significantly different from the mean predenervation ratio of 1.03 .

4. The disappearance of the denervation natriuresis when filtered sodium was returned to predenervation values by clamping is evidence against a direct effect of renal nerves on tubular sodium reabsorption and indicates that acute denervation natriuresis results solely from increased GFR.

\section{References}

1. Berne, R. M. Hemodynamics and sodium excretion of denervated kidney in anesthetized and unanesthetized dog. Amer. J. Physiol. 1952, 171, 148.

2. Surtshin, A., and W. P. Schmandt. Comparison of continuously collected urine from two normal kidneys and some effects of unilateral denervation. Amer. J. Physiol. 1956, 185, 418.

3. Page, L. B., C. F. Baxter, G. H. Reem, J. C. ScottBaker, and H. W. Smith. Effect of unilateral splanchnic nerve resection on the renal excretion of sodium. Amer. J. Physiol. 1954, 177, 194.

4. Surtshin, A., C. B. Mueller, and H. L. White. Effect of acute changes in glomerular filtration rate on water and electrolyte excretion: mechanism of denervation diuresis. Amer. J. Physiol. 1952, 169, 159.
5. Bricker, N. S., R. A. Straffon, E. P. Mahoney, and J. P. Merrill. The functional capacity of the kidney denervated by autotransplantation in the dog. J. clin. Invest. 1958, 37, 185.

6. Kriss, J. P., P. H., Futcher, and M. L. Goldman. Unilateral adrenalectomy, unilateral splanchnic nerve resection and homolateral renal function. Amer. J. Physiol. 1948, 154, 229.

7. Kaplan, S. A., and S. Rapoport. Urinary excretion of sodium and chloride after splanchnicotomy; effect on the proximal tubule. Amer. J. Physiol. 1951, 164, 175.

8. Kaplan, S. A., S. J. Fomon, and S. Rapoport. Effect of splanchnic nerve division on urinary excretion of electrolytes during mannitol loading in the hydropenic dog. Amer. J. Physiol. 1951, 166, 641.

9. Kaplan, S. A., C. D. West, and S. J. Fomon. Effect of unilateral division of splanchnic nerve on the renal excretion of electrolytes in unanesthetized and anesthetized dogs: the mechanism of "crossed stimulation." Amer. J. Physiol. 1953, 175, 363.

10. Sartorius, O. W., and H. Burlington. Acute effects of denervation on kidney function in the dog. Amer. J. Physiol. 1956, 185, 407.

11. Fisher, A., and L. Takacs. Die Neuroregulation der tubularen Nierenfunktion in Nierenfunktion und Nervensystem, H. Dutz, Ed. Berlin, VEB Verlag Volk und Gesundheit, 1959, p. 63.

12. Blake, W. D. Relative roles of glomerular filtration and tubular reabsorption in denervation diuresis. Amer. J. Physiol. 1962, 202, 777.

13. Levinsky, N. G., and R. C. Lalone. The mechanism of sodium diuresis after saline infusion in the dog. J. clin. Invest. 1963, 42, 1261.

14. Tobian, L., K. Coffee, D. Ferreira, and J. Meuli. The effect of renal perfusion pressure on the net transport of sodium out of distal tubular urine as studied with the stop-flow technique. J. clin. Invest. 1964, 43, 118.

15. Selkurt, E. E. Effect of pulse pressure and mean arterial pressure modification on renal hemodynamics and electrolyte and water excretion. Circulation 1951, 4, 541.

16. Mueller, C. B., A. Surtshin, M. R. Carlin, and H. L. White. Glomerular and tubular influences on sodium and water excretion. Amer. J. Physiol. 1951, 165, 411.

17. Wesson, L. G., Jr. Glomerular and tubular factors in the renal excretion of sodium chloride. Medicine (Baltimore) 1957, 36, 281.

18. Thompson, D. D., M. J. Barrett, and R. F. Pitts. Significance of glomerular perfusion in relation to variability of filtration rate. Amer. J. Physiol. 1951, 167, 546.

19. Davidson, D. G., N. G. Levinsky, and R. W. Berliner. Maintenance of potassium excretion despite reduction of glomerular filtration during sodium diuresis. J. clin. Invest. 1958, 37, 548.

20. Coelho, J. B., and S. E. Bradley. Function of the nephron population during hemorrhagic hypoten- 
sion in the dog, with special reference to the effects of osmotic diuresis. J. clin. Invest. 1964, 43, 386.

21. Berliner, R. W. Seminars on renal physiology. Renal excretion of water, sodium, chloride, potassium, calcium and magnesium. Amer. J. Med. 1950, 9, 541.

22. De Wardener, H. E., I. H. Mills, W. F. Clapham, and C. J. Hayter. Studies on the efferent mechanism of the sodium diuresis which follows the administration of intravenous saline in the dog. Clin. Sci. 1961, 21, 249.

23. Rector, F. C., Jr., G. Van Giesen, F. Kiil, and D. W. Seldin. Influence of expansion of extracellular volume on tubular reabsorption of sodium independent of changes in glomerular filtration rate and aldosterone activity. J. clin. Invest. 1964, 43, 341.

24. Wesson, L. G., Jr., W. P. Anslow, Jr., and H. W. Smith. The excretion of strong electrolytes. Bull. N. Y. Acad. Med. 1948, 24, 586.

25. Wesson, L. G., Jr., W. P. Anslow, L. G. Raisz, A. A. Bolomey, and M. Ladd. Effect of sustained expansion of extracellular fluid volume upon filtration rate, renal plasma flow and electrolyte and water excretion in the dog. Amer. J. Physiol. 1950, 162, 677. 